\title{
DESIGN OF NONWOVEN CARPETS TO UPGRADE SOUND ISOLATION FEATURES IN AUTOMOBILES
}

\author{
Raziye Atakan ${ }^{1}$, Hale Karakaş${ }^{1}$, Serdar Sezer $^{2}$, Süleyman İpek1, İpek Aravi ${ }^{1}$, Cansu Yıldırım¹, Ezgi Şen ${ }^{1}$
}

${ }^{1}$ Textile Technologies and Design Faculty, Textile Engineering Department, İnönü cad. No: 65, 34437, Gümüşsuyu, Taksim, Istanbul, Turkey ${ }^{2}$ Research Development Department, Pelzer Pimsa Otomotiv A.Ş.-Gebze, Turkey

ratakan@itu.edu.tr, karakashal@itu.edu.tr, ssezer@pelzerpimsa.com.tr, suleymanipek@gmail.com, aravi@itu.edu.tr, cansu.yildirim.89@hotmail.com, ezgisen89@gmail.com

Abstract:

With the increases of the expected properties of textile products, better and advanced new designs are being created. Textiles used in vehicles are increasing, and the current performance of the expectations bar is determined by automobile manufacturers. While meeting the expectations of users in the vehicle mechanically, but also disturbing the user during operation of the mechanical properties of this ratio should be minimized. This study was intended to minimize sound transmission of nonwoven textile components, which are used in cars as silencer parts. For that purpose, four different models were developed in this study. First model consists of three designs for baggage carpets. Second model has six designs for floor coverings. Third model comprises two designs inner dash felt and finally fourth model includes two designs of hood liners. The acoustical absorption coefficients and transmission loss of these carpets were tested and evaluated in the frequency range of 16-6300 $\mathrm{Hz}$. The measurements demonstrated that nonwoven layer is a very significant and effective part of a carpet due to its contribution in the sound isolation. With this study, it has been determined which layer has better performance on sound absorption and transmission loss among different carpet types. A combination of heavy layer and nonwoven layer carpets is found to be benefit for noise and sound insulation.

\section{Keywords:}

Nonwoven automotive carpet, impedance tube, sound absorption, transmission loss.

\section{Introduction}

The expansion of the industrial textile market is good for the textile industry, and automotive textiles in particular are frequent in the media. As shown in Figure 1.1, proportional to the increase of global motor vehicle production, the use of automotive textiles keeps growing (Chapman, 2010).

New materials, usage, techniques, and applications are growing extensively due to cost and performance. However, their usage is far more than just reducing cost and weight. Nonwovens often do their job better than other products. A good example is acoustics or noise control. Low road noise is often a factor in a sense of "quality". In manufacturing, nonwovens are often more easily conformed to shapes to help in the fabricating process. Frequently, they offer better "value-in-use" and can be engineered to have specific properties, whether balanced or unidirectional, and can often be combined with other materials, most often woven or knit textiles, in a beneficial way. Over 40 automotive parts utilize engineered nonwovens and the list is growing (Smith, 2004).

\begin{tabular}{|l|r|r|r|r|r|}
\hline \multicolumn{6}{|c|}{ Worldwide production of automotive textiles } \\
\hline & 1985 & 1990 & 1995 & 2000 & 2005 \\
\hline & 953 & 1,125 & 1,170 & 1,221 & 1,214 \\
\hline Fabrics, Knits & 95 & 109 & 107 & 111 & 114 \\
\hline Nonwovens & 284 & 443 & 521 & 736 & 976 \\
\hline Composites & 76 & 97 & 119 & 152 & 179 \\
\hline Others & & & \multicolumn{4}{c|}{ Source: Frost \& Sullvan }
\end{tabular}

Figure 1.1: Worldwide production growth of automobile textiles (1,000 tonnes). 
Table 1.1 lists typical nonwoven applications for auto interior production. The biggest portion of the nonwoven usage in a car is carpet (in both passenger and trunk compartment areas) and insulation, accounting for $73 \%$ of the total nonwoven usage.

A breakdown of major nonwoven usage include areas such as carpet $(43 \%)$, headliner $(6 \%)$, hood liner $(10 \%)$, trunk $(13 \%)$, insulation $(17 \%)$, door panels $(1 \%)$, seating $(6 \%)$, package trays (3\%), and other miscellaneous areas (1\%) (Smith, 2004). Table 1.2 lists the parts of an automobile where nonwovens are used.

Table 1.1: Nonwovens as auto interior materials (Camelio, 2003).
A large volume automotive fabric, and a major target area for nonwovens, involves carpets. A typical structure of automotive carpet system includes a decorative layer of fibre, thermoplastic material for thermoforming and acoustic and vibration damping layer. The carpet interior has two functions: floor covering for aesthetical reasons and floor insulation for noise barrier and noise absorption.

One of the goals of automotive manufacturers today is to produce a vehicle with the highest possible noise

\begin{tabular}{|c|c|c|c|}
\hline Interior part & Component & $\begin{array}{c}\text { Nonwoven } \\
\text { area usage } \\
(\%)\end{array}$ & Nonwoven technology \\
\hline $\begin{array}{c}\text { Passenger } \\
\text { carpet }\end{array}$ & Decor fabric, first and second layer of underlayment & 43 & Needle-punch, spunbond \\
\hline Insulation & Acoustic and thermal insulators wherever needed & 17 & Needle-punch, spunbond \\
\hline Trunk trim & Floor cover, insulating layer, side liners & 13 & Needle-punch, spunbond \\
\hline $\begin{array}{c}\text { Rear shelf/ } \\
\text { package tray }\end{array}$ & Facing and backing fabrics & 3 & Needle-punch \\
\hline Hood liner & Absorbing layer & 10 & Needle-punch, spunbond \\
\hline Headliner & Decor fabric, insulator, substrate & 6 & Needle-punch, spunbond, spunlacing \\
\hline Seat & $\begin{array}{c}\text { Decor fabric, back fabric, bolster fabric, construction } \\
\text { reinforcement }\end{array}$ & 6 & Needle-punch, spunbond, spunlacing \\
\hline Door trim & Lower facing, panel trim (door insert/bolster) & 1 & Needle-punch, spunbond, spunlacing \\
\hline Miscellaneous & $\quad$ & 1 & \\
\hline
\end{tabular}

Table 1.2: Where nonwovens are used in an automobile (Smith, 2004).

\begin{tabular}{|c|c|c|}
\hline Face Material & Construction & Filtration \\
\hline Seating & Seating & Engine Air \\
\hline Headliners & Headliner & Interior Air \\
\hline Carpets & Carpets & Transmission \\
\hline Trunk Liner & Door/Dash Panels & Oil \\
\hline Package Tray & Acoustic & Brake hose \\
\hline Door Panel andTrim & Adhesives & \\
\hline \multirow[t]{8}{*}{ Pillar Cover } & Fire Blocker & \\
\hline & Other & \\
\hline & Battery Separators & \\
\hline & Tire reinforcement & \\
\hline & Electrical insulation & \\
\hline & Gaskets/Seals & \\
\hline & Muffler & \\
\hline & Catalytic converter & \\
\hline
\end{tabular}


absorption, as the hazards from noise are diversity and harmful. It not only seriously affects human health, it also affects the life of buildings and equipment [Hong Z. et al, 2004, Yuheng L., 2001]. More and more people have gradually realized that noise has become a huge hazard to human health and environmental pollution. Therefore, effective prevention of noise pollution has become a hot topic around the world. The ability to reduce noise inside the vehicle enhances the perceived value of the vehicle to the consumer and offers a competitive advantage to the manufacturer [Ming M. et al, 2011]. Therefore, engineers working in research departments at carpet manufacturers as well as universities apply much effort to the reduction of noise and vibration in an automobile. These efforts are made by using sound absorptive materials and by designing structural compositions.

The silencer parts that researched in this study are included at every car although they are ignored or even unknown by customers who purchased. The components included are floor carpet, trunk carpet, felts under the hood, etc. This seemingly minor parts cost very little and as a result of research and development activities, fairly high level of sound insulation and in-car comfort can be provided.

In fact, simple plugins and coatings to the car components to reduce the noise level in the car is a fairly simple process. By $10 \%$ of investment costs of the optional seat heating system fitted to the vehicle, all the parts in the car can be produced to absorb $30 \%$ more sound. The results of this study are also a proof of this theory.

\section{EXPERIMENTAL STUDY}

\subsection{Materials}

The materials used in the design and development of sound absorber nonwovens include SBR Latex, polyester fibre that has a form of nonwoven carpet, PE powder and hard layer, which is composed of polyester, polypropylene and bicomponent fibres, heavy layer that is felt made of EVA rubber or EPDM.

\subsection{Modelling of Nonwovens}

\subsubsection{Model I}

For the baggage carpets, three models were designed, which is shown in Table 2.1.

The designs consist of felt as the upper layer for absorbing, and hard or heavy layer as the lower layer, which is involved for transmission loss function. In between, there are SBR latex and $\mathrm{PE}$ for binding purposes in the models.

\subsubsection{Model II}

For the floor carpets, six models were designed, which is shown in Table 2.2.

In these models, as the same as luggage carpets, felt functions as an absorbing layer. Heavy and hard layer provide transmission loss properties. SBR Latex and PE are binders in between the upper and the lower layers.

Table 2.1 Model Designs of Baggage Carpets.

\begin{tabular}{|c|c|c|c|}
\hline Name & Baggage Carpet-1 & Baggage Carpet-2 & Baggage Carpet-3 \\
\hline Felt $(\mathrm{g})$ & 200 & 200 & 50 \\
\hline SBR Latex (g) & 50 & 50 & 80 \\
\hline PE $(\mathrm{g})$ & 80 & 80 & \\
\hline Hard layer (g) & 500 & & 1600 \\
\hline Heavy layer (g) & & 1200 & \\
\hline
\end{tabular}

Table 2.2 Model Designs of Floor Carpets.

\begin{tabular}{|c|c|c|c|c|c|c|}
\hline \multirow{2}{*}{ Name } & F. Carpet-1 & F. Carpet-2 & F. Carpet-3 & F. Carpet-4 & F. Carpet-5 & F. Carpet-6 \\
\cline { 2 - 6 } & $\mathbf{( 1 2 0 0} \mathbf{~ g )}$ & $\mathbf{( 1 6 0 0 ~ g )}$ & & & 600 \\
\hline Felt (g) & 500 & 500 & 400 & 600 & 100 & 700 \\
\hline SBR Latex (g) & 80 & 80 & 80 & & 500 & 100 \\
\hline PE (g) & 80 & 80 & 80 & 500 & & 2300 \\
\hline Heard layer (g) & 1200 & 1600 & 500 & & & \\
\hline
\end{tabular}




\subsubsection{Model III}

For inner dash felts, two models that comprise the upper layers of thermoplastic felt and polyurethane for absorbing function and heavy layer for transmission function were designed (Figure 2.1).

\begin{tabular}{|c|}
\hline Thermoplastic felt \\
\hline Heavy layer \\
\hline
\end{tabular}

\begin{tabular}{|c|}
\hline Polyurethane \\
\hline Heavy layer \\
\hline
\end{tabular}

Figure 2.1 Model designs of inner dash felts.

\subsubsection{Model IV}

In the models of hood liners in the car, absorbing felt, which consists of different components, was used instead of heavy or hard layer where transmission loss is obtained (Figure 2.2).

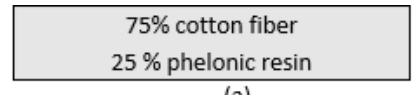

(a)

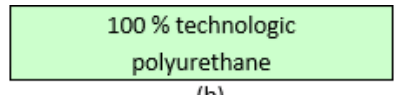

(b)
Figure 2.2 Model Designs of hood liners.

\subsection{Development of Nonwovens}

Each web was processed through the needle-punching machine three times to develop the complete nonwoven.

\subsection{Sound Absorption Coefficient and Transmission Loss Testing by Impedance Tube Method (ASTM E 1050)}

The sound absorption is one of the most important acoustical properties of the porous materials used for sound insulation products having the role of sound barriers, walls, and road surfaces [Curtu I., 2010]. Depending on the type of materials and products, the range of frequencies and applications, the measurement methods of absorption coefficient vary and they can be: the impedance tube method, ultrasound method, extended surface method, guard tube method or reverberant room method [Grimberg R. et al, 2011]. One of the widely used methods to determine the acoustic properties (absorption coefficient, impedance ratio, reflection coefficient) is the international standardized impedance tube method, which is shown in Figure 2.3.

To determine the absorption coefficients, the set-up measurement chain presented in Figure 2.4 was used.

First, the equipment without samples was prepared, to configure the microphones and to calibrate them using the calibration function from Pulse soft [ISO 10534-1:1996 Part 1, SR EN ISO 10534-2 Part 2]. Then, each sample was properly inserted into the tube and the measurements started. The generated noise was connected to the amplifier and the tube filter emitted the set signals. The emitted signal and reflected signal were captured by microphones and transmitted to Pulse hardware and displayed with the Pulse soft.

The acoustical properties of the test sample were tested in the frequency range of $16-6300 \mathrm{~Hz}$. This system tests a sound absorptive material, processes the results and reports the results in a graph of the absorption coefficient in various frequencies. Thus, the absorption coefficient of each sample was obtained.

\section{RESULTS AND DISCUSSIONS}

\subsection{Sound Absorption Test Results of Model I}

The sound absorption test results of baggage carpets are shown in Table 3.1 and Figure 3.1.

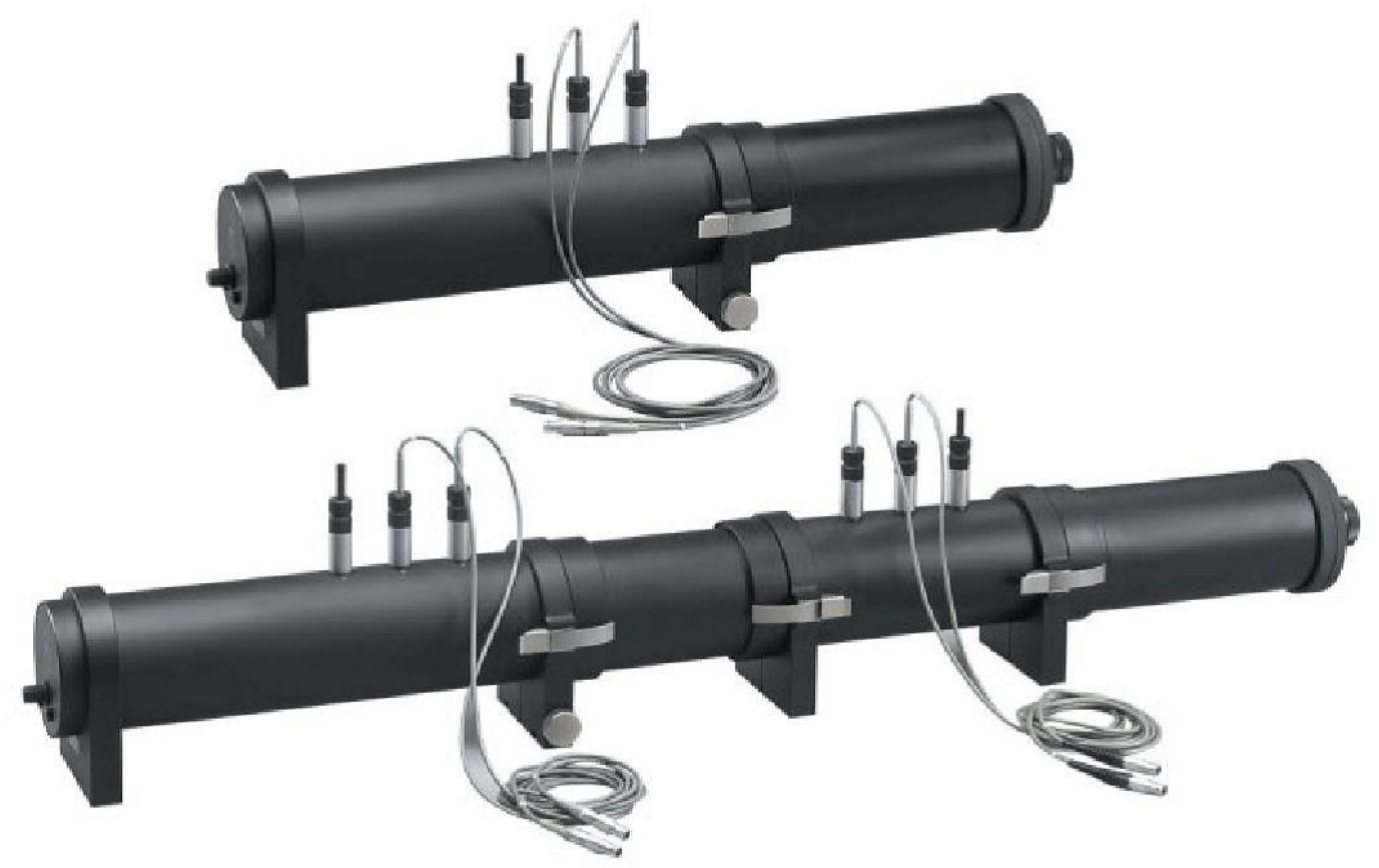

Figure 2.3. Single and double impedance tube kits. 


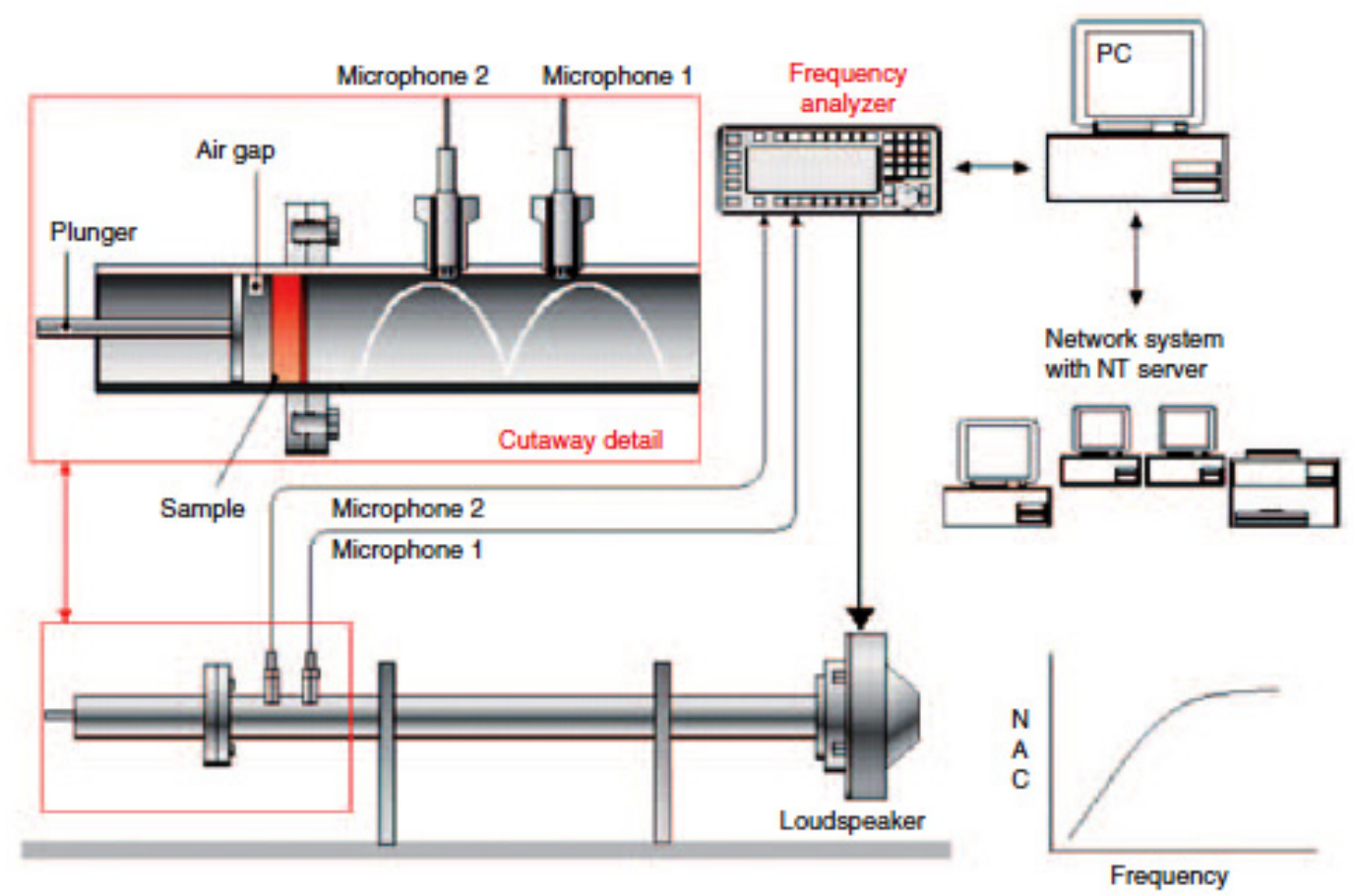

Figure 2.4. Schematic sketch of an impedance tube set up.

Table 3.1. Sound absorption test results for luggage carpet models.

\begin{tabular}{|c|c|c|c|}
\hline Name: & Baggage Carpet-1 & Baggage Carpet-2 & Baggage Carpet-3 \\
\hline $\mathrm{f}(\mathrm{Hz})$ & Real Part & Real Part & Real Part \\
\hline 16 & 0.2 & 0.2 & 0.19 \\
\hline 20 & 0.16 & 0.19 & 0.18 \\
\hline 25 & 0.17 & 0.17 & 0.17 \\
\hline 31.5 & 0.12 & 0.11 & 0.12 \\
\hline 40 & 0.11 & 0.1 & 0.1 \\
\hline 50 & 0.08 & 0.08 & 0.08 \\
\hline 63 & 0.05 & 0.05 & 0.05 \\
\hline 80 & 0.03 & 0.03 & 0.04 \\
\hline 100 & 0.02 & 0.02 & 0.03 \\
\hline 125 & 0.01 & 0.01 & 0.01 \\
\hline 160 & 0.01 & 0.02 & 0.02 \\
\hline 200 & 0.02 & 0.02 & 0.02 \\
\hline 250 & 0.02 & 0.02 & 0.03 \\
\hline 315 & 0.02 & 0.02 & 0.03 \\
\hline 400 & 0.02 & 0.02 & 0.04 \\
\hline 500 & 0.02 & 0.03 & 0.04 \\
\hline 630 & 0.03 & 0.05 & 0.07 \\
\hline 800 & 0.05 & 0.07 & 0.12 \\
\hline 1000 & 0.06 & 0.1 & 0.14 \\
\hline 1250 & 0.07 & 0.12 & 0.16 \\
\hline 1600 & 0.08 & 0.15 & 0.17 \\
\hline 2000 & 0.1 & 0.19 & 0.22 \\
\hline 2500 & 0.12 & 0.26 & 0.3 \\
\hline 3150 & $0 . .21$ & 0.38 & 0.41 \\
\hline 4000 & 0.31 & 0.55 & 0.54 \\
\hline 5000 & 0.4 & 0.67 & 0.68 \\
\hline 6300 & 0.47 & 0.79 & 0.68 \\
\hline
\end{tabular}


According to the results in Table 3.1, the rates of sound absorption increases with the increase of frequency values. At the $6300 \mathrm{~Hz}$, Sample 2 has $79 \%$, Sample 3 has $68 \%$ sound absorption capacities, while sample 1 has only $47 \%$ capacity. It shows that Sample 2 is the most effective design among these models.

Sample 1 has three layers, the others comprise four layers. Amongst the four-layer composites models, strongest absorption value was found with the sample consisting of 1200 $\mathrm{g}$ heavy layer.

\subsection{Sound Absorption Test Results of Model II}

Table 3.2 and Figure 3.2 demonstrate the sound absorption test results of floor carpet models.

In the light of values in the table, Sample-1 has had the highest sound absorption performance. $80 \%$ of sound absorption has been provided at $6300 \mathrm{~Hz}$.

\subsection{Sound Absorption Test Results of Model III}

Table 3.3 and Figure 3.3 show the sound absorption test results of inner dash felt models.

\subsection{Sound Absorption Test Results of Model IV}

The sound absorption test results of hood liners are shown in Table 3.4 and Figure 3.4.

\subsection{Transmission Loss Test Results of Model I}

Transmission loss test results of baggage carpets are shown in Table 3.5 and Figure 3.5.

\subsection{Transmission Loss Test Results of Model II}

Transmission loss test results of floor carpets are shown in Table 3.6 and Figure 3.6.

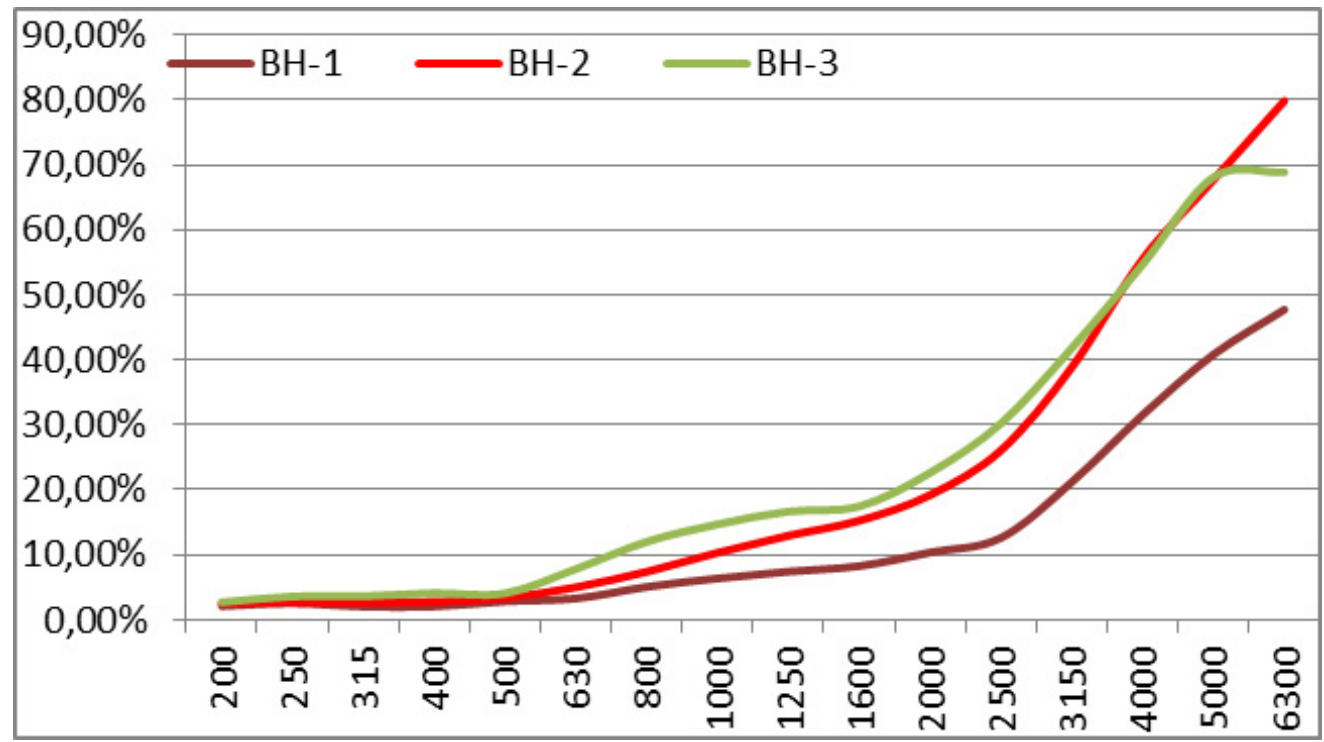

Figure 3.1. Sound absorption graphs of baggage carpet models.

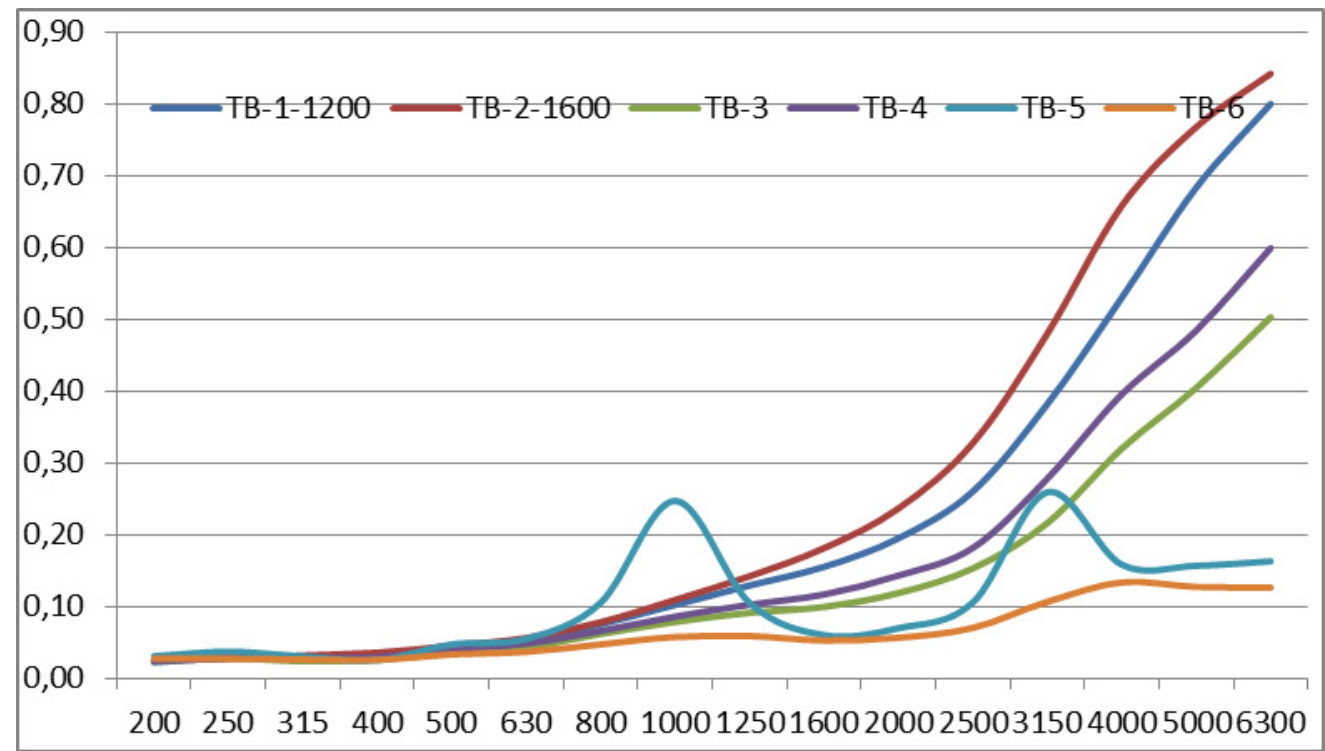

Figure 3.2. Sound absorption graphs of floor carpet models. 
Table 3.2. Sound absorption test results for floor carpet models.

\begin{tabular}{|c|c|c|c|c|c|c|}
\hline Name: & F. Carpet-1-1200 & F. Carpet-2-1600 & F. Carpet-3 & F. Carpet-4 & F. Carpet-5 & F. Carpet- 6 \\
\hline$f(H Z)$ & Real Part & Real Part & Real Part & Real Part & Real Part & Real Part \\
\hline 16 & 0.22 & 0.23 & 0.23 & 0.22 & 0.21 & 0.25 \\
\hline 20 & 0.2 & 0.21 & 0.17 & 0.19 & 0.19 & 0.24 \\
\hline 25 & 0.16 & 0.14 & 0.17 & 0.15 & 0.18 & 0.13 \\
\hline 31.5 & 0.14 & 0.13 & 0.12 & 0.14 & 0.15 & 0.14 \\
\hline 40 & 0.1 & 0.1 & 0.11 & 0.11 & 0.12 & 0.12 \\
\hline 50 & 0.08 & 0.09 & 0.1 & 0.09 & 0.09 & 0.1 \\
\hline 63 & 0.05 & 0.05 & 0.06 & 0.06 & 0.06 & 0.05 \\
\hline 80 & 0.04 & 0.04 & 0.03 & 0.04 & 0.05 & 0.04 \\
\hline 100 & 0.03 & 0.03 & 0.03 & 0.03 & 0.04 & 0.03 \\
\hline 125 & 0.02 & 0.02 & 0.02 & 0.02 & 0.03 & 0.02 \\
\hline 160 & 0.02 & 0.02 & 0.03 & 0.03 & 0.03 & 0.03 \\
\hline 200 & 0.02 & 0.02 & 0.02 & 0.02 & 0.03 & 0.03 \\
\hline 250 & 0.03 & 0.03 & 0.03 & 0.03 & 0.04 & 0.03 \\
\hline 315 & 0.03 & 0.03 & 0.02 & 0.03 & 0.03 & 0.03 \\
\hline 400 & 0.03 & 0.04 & 0.03 & 0.03 & 0.03 & 0.03 \\
\hline 500 & 0.04 & 0.05 & 0.03 & 0.04 & 0.05 & 0.03 \\
\hline 630 & 0.05 & 0.06 & 0.04 & 0.05 & 0.05 & 0.04 \\
\hline 800 & 0.08 & 0.08 & 0.06 & 0.07 & 0.11 & 0.05 \\
\hline 1000 & 0.1 & 0.11 & 0.08 & 0.09 & 0.25 & 0.06 \\
\hline 1250 & 0.13 & 0.14 & 0.09 & 0.1 & 0.1 & 0.06 \\
\hline 1600 & 0.16 & 0.18 & 0.1 & 0.12 & 0.06 & 0.05 \\
\hline 2000 & 0.19 & 0.24 & 0.12 & 0.14 & 0.07 & $0 . .06$ \\
\hline 2500 & 0.26 & 0.33 & 0.15 & 0.18 & 0.11 & 0.07 \\
\hline 3150 & 0.38 & 0.48 & 0.22 & 0.28 & 0.26 & 0.11 \\
\hline 4000 & 0.53 & 0.66 & 0.32 & 0.4 & 0.16 & 0.13 \\
\hline 5000 & 0.68 & 0.77 & 0.4 & 0.48 & 0.16 & 0.13 \\
\hline 6300 & 0.8 & 0.84 & 0.5 & 0.6 & 0.16 & 0.13 \\
\hline
\end{tabular}

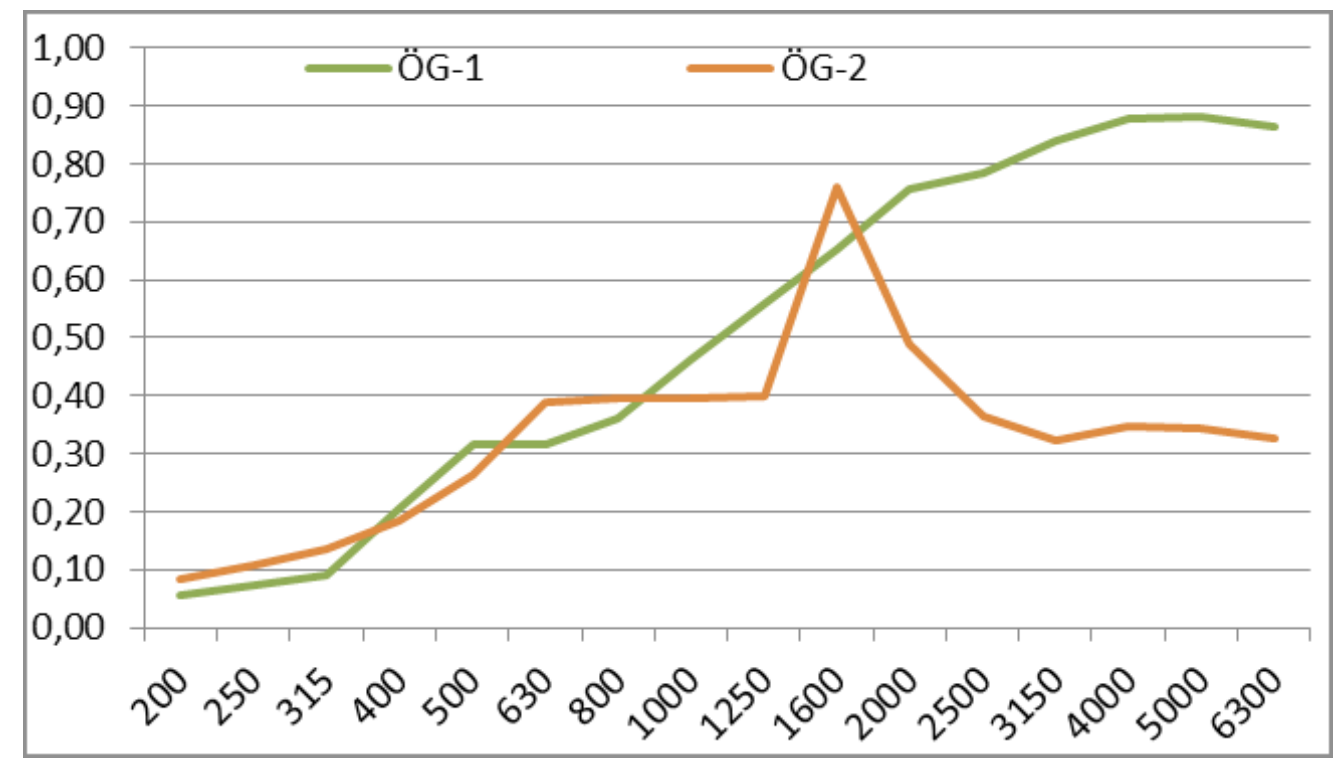

Figure 3.3. Sound absorption graphs of inner dash felt models. 
Table 3.3. Sound absorption test results for inner dash felt models.

\begin{tabular}{|c|c|c|}
\hline Name: & Inner Dash Felt-1 & Inner Dash Felt-1 \\
\hline $\mathbf{f}(\mathrm{HZ})$ & Real Part & Real Part \\
\hline 16 & 0,19 & 0,21 \\
\hline 20 & 0,19 & 0,2 \\
\hline 25 & 0,16 & 0,16 \\
\hline 31,5 & 0,14 & 0,14 \\
\hline 40 & 0,12 & 0,11 \\
\hline 50 & 0,09 & 0,1 \\
\hline 63 & 0,07 & 0,07 \\
\hline 80 & 0,06 & 0,06 \\
\hline 100 & 0,04 & 0,05 \\
\hline 125 & 0,04 & 0,05 \\
\hline 160 & 0,05 & 0,07 \\
\hline 200 & 0,06 & 0,08 \\
\hline 250 & 0,07 & 0,11 \\
\hline 315 & 0,09 & 0,14 \\
\hline 400 & 0,21 & 0,18 \\
\hline 500 & 0,32 & 0,26 \\
\hline 630 & 0,32 & 0,39 \\
\hline 800 & 0,36 & 0,39 \\
\hline 1000 & 0,46 & 0,39 \\
\hline 1250 & 0,56 & 0,4 \\
\hline
\end{tabular}

\begin{tabular}{|c|c|c|}
\hline Name: & Hood liner-1 & Hood liner-2 \\
\hline $\mathbf{f}(\mathrm{Hz})$ & Real Part & Real Part \\
\hline 16 & 0,2 & 0,21 \\
\hline 20 & 0,2 & 0,2 \\
\hline 25 & 0,14 & 0,14 \\
\hline 31,5 & 0,14 & 0,13 \\
\hline 40 & 0,11 & 0,11 \\
\hline 50 & 0,09 & 0,09 \\
\hline 63 & 0,05 & 0,06 \\
\hline 80 & 0,04 & 0,05 \\
\hline 100 & 0,03 & 0,04 \\
\hline 125 & 0,03 & 0,04 \\
\hline 160 & 0,03 & 0,03 \\
\hline 200 & 0,04 & 0,04 \\
\hline 250 & 0,04 & 0,05 \\
\hline 315 & 0,05 & 0,05 \\
\hline 400 & 0,05 & 0,06 \\
\hline 500 & 0,07 & 0,07 \\
\hline 630 & 0,11 & 0,1 \\
\hline 800 & 0,18 & 0,14 \\
\hline 1000 & 0,25 & 0,2 \\
\hline 1250 & 0,36 & 0,27 \\
\hline 1600 & 0,48 & 0,32 \\
\hline 2000 & 0,6 & 0,43 \\
\hline 2500 & 0,73 & 0,53 \\
\hline 3150 & 0,88 & 0,75 \\
\hline 4000 & 0,98 & 0,88 \\
\hline 5000 & 1 & 0,99 \\
\hline 6300 & 0,97 & 0,96 \\
\hline
\end{tabular}

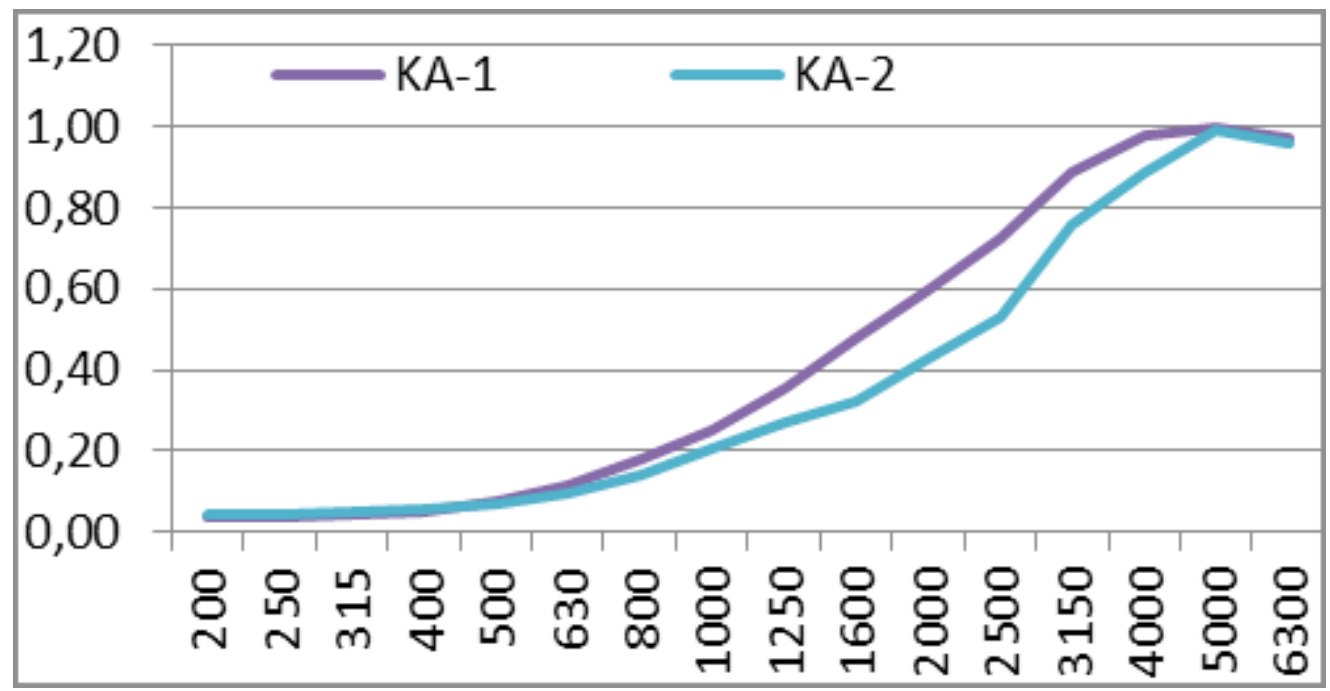

Figure 3.4. Sound absorption graphs of inner dash felt models. 
Table 3.5. Transmission loss test results for baggage carpet models.

\begin{tabular}{|c|c|c|c|c|}
\hline \multirow{2}{*}{$\begin{array}{l}\text { Name } \\
f(H z)\end{array}$} & \multirow{2}{*}{ Baggage Carpet-1 } & \multirow{2}{*}{ Baggage Carpet-2 } & \multirow{2}{*}{ Baggage Carpet-3 } & \multirow{2}{*}{$\begin{array}{c}\text { Baggage Carpet-4 (more heavy } \\
\text { layer) }\end{array}$} \\
\hline & & & & \\
\hline 40 & 13,4023 & 15,1538 & 18,4291 & 28,9976 \\
\hline 50 & 11,922 & 13,5109 & 16,8505 & 29,0519 \\
\hline 63 & 10,4158 & 12,0292 & 15,3012 & 29,8718 \\
\hline 80 & 9,04037 & 10,5243 & 13,5848 & 27,8923 \\
\hline 100 & 7,82249 & 9,16588 & 12,0526 & 25,8443 \\
\hline 125 & 6,74468 & 7,96943 & 10,7087 & 24,4473 \\
\hline 160 & 5,84272 & 6,97596 & 9,54665 & 23,1889 \\
\hline 200 & 5,09722 & 6,15085 & 8,57748 & 22,1067 \\
\hline 250 & 4,50157 & 5,48933 & 7,82088 & 21,2704 \\
\hline 315 & 4,01705 & 4,98371 & 7,24946 & 20,7623 \\
\hline 400 & 3,62389 & 4,56539 & 6,80621 & 20,7732 \\
\hline 500 & 3,29692 & 4,23903 & 6,47162 & 19,7313 \\
\hline 630 & 3,02375 & 3,95895 & 6,16578 & 19,1864 \\
\hline 800 & 2,82265 & 3,72401 & 5,86569 & 19,1147 \\
\hline 1000 & 2,74902 & 3,62133 & 5,69377 & 19,4698 \\
\hline 1250 & 2,82975 & 3,72939 & 5,85922 & 19,2216 \\
\hline 1600 & 3,01065 & 3,97644 & 6,19063 & 19,1272 \\
\hline 2000 & 3,01456 & 4,0463 & 6,24771 & 18,6519 \\
\hline 2500 & 2,72695 & 3,9252 & 6,06765 & 17,1426 \\
\hline 3150 & 3,06146 & 3,93548 & 5,82515 & 12,5003 \\
\hline 4000 & 3,03743 & 4,02989 & 6,04318 & 12,6996 \\
\hline 5000 & 3,16586 & 4,23546 & 6,34506 & 15,4295 \\
\hline
\end{tabular}

\subsection{Discussions of the Results}

While designing the models, layer components were determined according to the material properties. The materials situated on the top layer with more volume, porous structure and low density have better sound absorption performance, while the lower layer material in the composite comprised highdensity materials.

The sound frequencies of four areas selected in the car are different. In the automobile textiles industry, textile materials used in the section of the dashboard and under the hood of the car are expected to show sound absorption performance. Therefore, it is focused on only sound absorption performance for these areas and these tests were performed. In test samples designed for the dashboard, obtained result of sample-1 was better due to the use of thermoplastic felts. In the tests of hood liners, the sample including phenol + cotton felt was found to have better sound absorption performance. This proves that the felt is a strongly necessary component for sound absorption properties of automobile textiles.
The materials for floor carpeting were used to improve the acoustic in the car. For the acoustic properties, the heavy layer and hard layer materials were clearly found to come out in sound absorption and transmission loss test performance.

In the baggage carpet design, it is aimed to increase sound absorption of outside noise coming into the passenger area. Sample-2 had better results in the sound absorption, and Sample-4 was fairly found to have better results in transmission loss tests. Both samples consist of heavy layer.

\section{CONCLUSIONS}

The aim of the study was to develop and design different layering composites for improving the sound insulation properties of silencer parts in the car. Four different models were designed and produced by needle punching. Absorption coefficients and acoustic impedance results have been evaluated. 


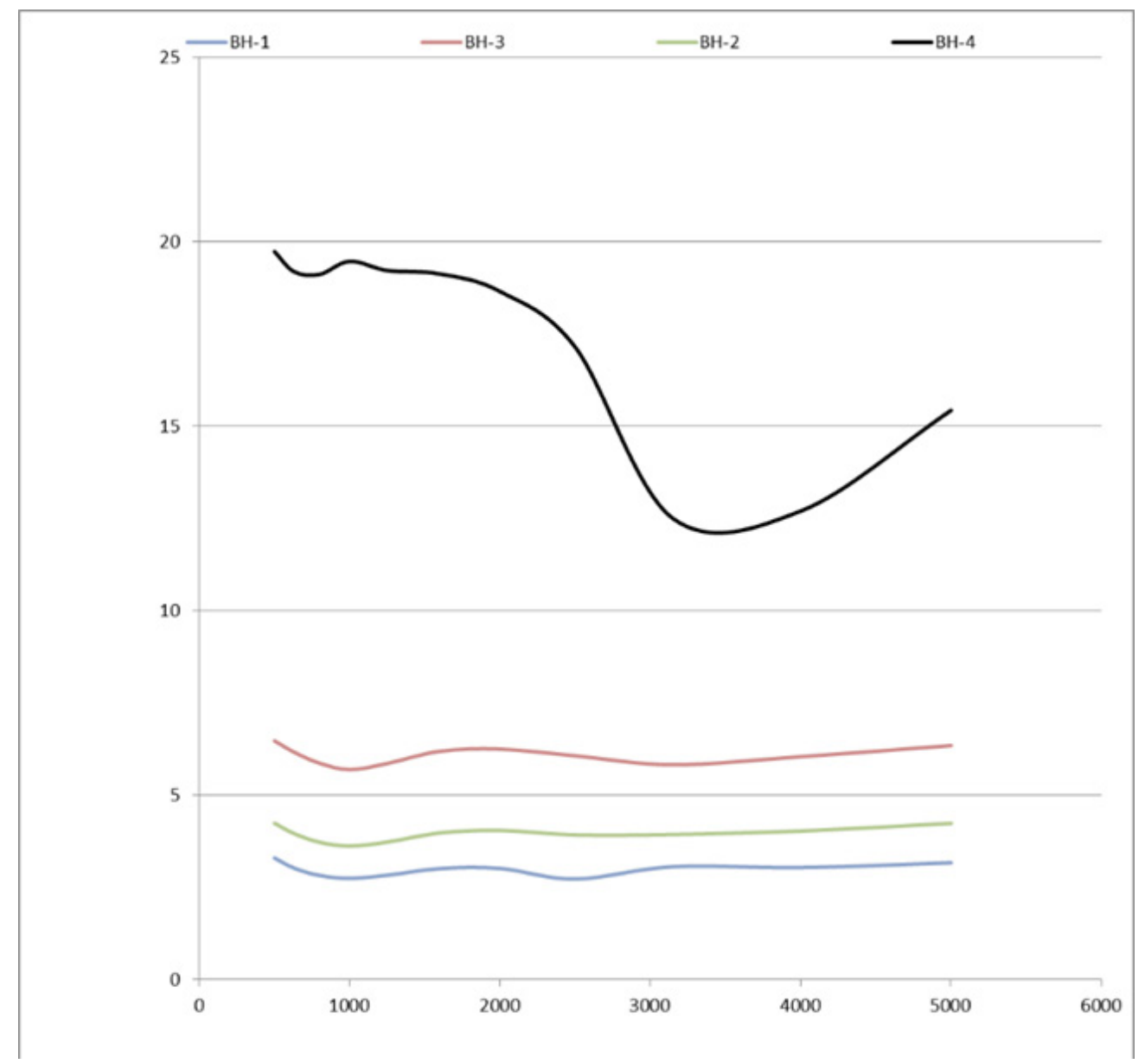

Figure 3.5. Transmission loss graphs of baggage carpet models.

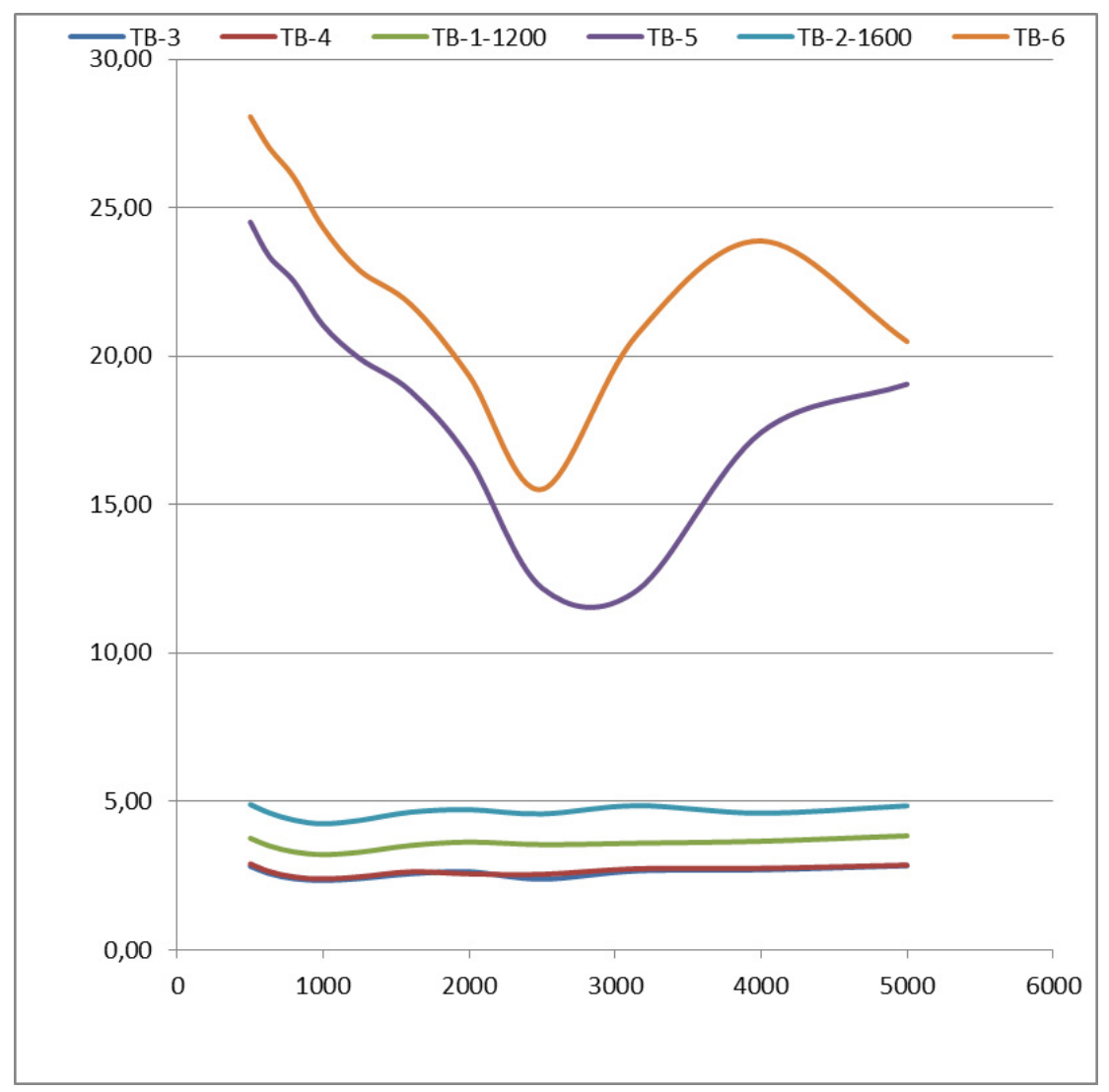

Figure 3.6. Transmission loss graphs of floor carpet models. 
Table 3.6. Transmission loss test results for floor carpet models.

\begin{tabular}{|c|c|c|c|c|c|c|}
\hline Name & F. Carpet-1 (1200) & F. Carpet-2 (1600) & F. Carpet-3 & F. Carpet-4 & F. Carpet-5 & F. Carpet-6 \\
\hline $\mathbf{f ( H z )}$ & & 16.04 & 12.26 & 12.44 & 38.31 & 37.09 \\
\hline 40 & 14.31 & 14.62 & 10.88 & 11.06 & 33.04 & 38.4 \\
\hline 50 & 12.74 & 13.05 & 9.44 & 9.61 & 29.59 & 35.59 \\
\hline 63 & 11.16 & 11.42 & 8.19 & 8.35 & 31.52 & 34.61 \\
\hline 80 & 9.74 & 10.03 & 7.05 & 7.19 & 32.09 & 34.08 \\
\hline 100 & 8.46 & 8.78 & 6.05 & 6.17 & 29.6 & 34.63 \\
\hline 125 & 7.32 & 7.73 & 5.22 & 5.33 & 35.54 & 34.61 \\
\hline 160 & 6.37 & 6.86 & 4.53 & 4.62 & 30.02 & 34.43 \\
\hline 200 & 5.59 & 6.16 & 3.96 & 4.05 & 29.28 & 32.26 \\
\hline 250 & 4.96 & 5.64 & 3.51 & 3.6 & 27.11 & 31.16 \\
\hline 315 & 4.47 & 5.22 & 3.13 & 3.2 & 26.11 & 28.54 \\
\hline 400 & 4.08 & 4.9 & 2.82 & 2.9 & 24.52 & 28.07 \\
\hline 500 & 3.76 & 4.62 & 2.57 & 2.64 & 23.36 & 27.02 \\
\hline 630 & 3.51 & 4.37 & 2.4 & 2.46 & 22.51 & 26.01 \\
\hline 800 & 3.3 & 4.25 & 2.34 & 2.39 & 21.03 & 24.32 \\
\hline 1000 & 3.21 & 4.36 & 2.4 & 2.46 & 19.92 & 22.88 \\
\hline 1250 & 3.29 & 4.64 & 2.56 & 2.63 & 18.81 & 21.74 \\
\hline 1600 & 3.52 & 4.72 & 2.63 & 2.56 & 16.54 & 19.34 \\
\hline 2000 & 3.63 & 4.58 & 2.38 & 2.55 & 12.18 & 15.52 \\
\hline 2500 & 3.55 & 4.86 & 2.66 & 2.73 & 12.11 & 20.73 \\
\hline 3150 & 3.59 & 4.61 & 2.7 & 2.75 & 17.43 & 23.89 \\
\hline 4000 & 3.66 & 4.85 & 2.84 & 2.85 & 19.06 & 20.49 \\
\hline 5000 & 3.84 & & & & \\
\hline
\end{tabular}

The design models of dashboard felt, hood liner, floor carpet and baggage carpet provided sound insulation first with absorbing the noise coming from outside and secondly with sound transmission loss.

Through this process, products with a higher added value and lower costs have been obtained. Based on the experimental results, the composition of the tested materials will be improved in the future in order to obtain a good absorption of the sound at low frequencies.

\section{References}

Chapman, R. (2010). Applications of Nonwovens in Technical Textiles. Woodhead Publishing Limited, Cambridge, England.

Curtu I, Stanciu M.D., Timar. J, Rosca I.C., Cerbu C., Luca Motoc D., Natural Frequency and Damping of Composite Materials with Application in the Sound Barriers Structures, in Book- The Automobile and the Environment: International Congress of Automotive and Transport Engineering CONAT 2010, edited by Anghel Chiru, Cambridge Scholars Publishing, 2011, p. 507.
Edana-automotive-nonwovens-newsletter-issue-june-2013, date retrieved 23.11.2013

Grimberg, R., Savin A., Steigmann R., Eftimie N., Stanciu M.D, A method to determine the debonding zones in multilayers wood materials, in Proceedings of the 8th International Conference Wood Science and Engineering in the Third Millennium" ICWSE2011, November 3-5, 2011, pp.403

Hong. Zhou, Guangsu. Huang, Xirong. Chen et al, (2004), Chemical Progress, Vol.16, n.3, 450-456, (In Chinese)

ISO 10534-1:1996 Acoustics - Determination of sound absorption coefficient and impedance in impedance tubes - Part 1: Method using standing wave ratio.

Ming Ma, Yuan Bai, Xiaoming Qian (2011), Advanced Materials Research Vols. 332-334 pp. 1531-1534

SR EN ISO 10534-2 Determination of sound absorption coefficient and acoustic impedance with the interferometer, Part 2: Transfer function method, 2002.

Smith, C.W. (2004). Nonwovens in Automotives- More than Just a Pretty Face. Industrial Textile Associates, Fall, 6063

Yuheng. Lv, (2001) Journal of Sound and Vibration, Vol.21, n.6, 14-17, (In Chinese) 